\title{
Leer lo ilegible. Sobre el proceso de lectura como fundamento de la crítica literaria
}

\author{
Leonardo Martínez Carrizales \\ Esther Martínez Luna
}

\begin{abstract}
Este artículo se propone replantear la idea de que el texto literario es un sistema cerrado y autosuficiente en virtud de los sistemas altamente formalizados que concurren en su configuración. Esta noción se ha sancionado teórica e institucionalmente gracias a la constitución de los estudios literarios como una disciplina universitaria. Los procedimientos de lectura crítica autorizados por la institución universitaria de los estudios literarios asumen plenamente el carácter sistemático de los códigos reconocidos en la construcción del texto literario. En cambio, en estas páginas se quiere plantear que el texto literario es uno más de los constituyentes de sentido radicalmente integrado con otras clases de constituyentes, lingüísticos y no lingüísticos, verbales y no verbales, dichos y no dichos. La idea de la radical integración del texto literario en un proceso complejo de la comunicación humana se ha desarrollado con base en las orientaciones teóricas del lingüista inglés Roy Harris, $y$, en opinión de este artículo, obligaría a todo lector crítico a reconocer la naturaleza circunstancial e histórica de los actos de comunicación que se integran en la escritura y en la lectura del texto.
\end{abstract}

Palabras Clave: lectura, crítica literaria, contextualización, lingüística integral.

This article proposes to rethink the idea that literary text is a closed and selfsufficient system by virtue of the highly formalized systems that appear in its configuration. This notion has been sanctioned theoretically and institutionally thanks to the existence of literary studies as a university discipline. The 
processes of critical reading authorized by the university institution of literary studies fully assume the systematic character of recognized codes in the construction of the literary text. On the other hand, in these pages one wishes to propose that literary text is one more constituent of meaning that is radically integrated with other constituent classes - linguistic and non-linguistic, verbal and non-verbal, spoken and unspoken. The idea of radical integration of literary text in a complex process of human communication has developed from a base of the theoretical guidelines of the English linguist Roy Harris, and, in the opinion of this article, would oblige every critical reader to recognize the circumstantial and historical nature of the acts of communication that are integrated in the writing and in the reading of the text.

KEYwORDS: reading, literary criticism, contextualization, integrationist linguistics.

Fecha de recepción: 4 de diciembre de 2011

Fecha de aceptación: 29 de marzo de 2012 
Leonardo Martínez Carrizales

Universidad Autónoma Metropolitana Azcapotzalco, México

Esther Martínez Luna

Universidad Nacional Autónoma de México

\section{Leer lo ilegible. Sobre el proceso de lectura como fundamento de la crítica literaria}

Este artículo se encuentra estrechamente relacionado con la experiencia personal que implica el cumplimiento de nuestras tareas como profesores universitarios adscritos al campo de los estudios literarios. Un campo cuyo patrimonio todavía se organiza y se distribuye de acuerdo con criterios tradicionalmente cronológicos, geográficos y políticos, al menos en el caso mexicano (literatura mexicana del siglo XIX y ensayo latinoamericano moderno son un ejemplo del tipo de categorías distributivas de dicho orden conceptual). ${ }^{1}$ Nuestro desempeño en un campo así regulado ha terminado por sumarnos al trabajo de diversos investigadores que, educados en diferentes disciplinas concernientes al lenguaje, el discurso, la sociedad, la recepción, la hermenéutica, los estudios culturales, la sociología de la cultura, la historia y la retórica, han

\footnotetext{
${ }^{1}$ Con la frase que da pie a esta nota queremos destacar que las categorías de análisis literario provenientes de una matriz retórico-filológica (obra, autor, tradición, prestigio, corpus textual, edición crítica, sistema) siguen imperando entre nosotros a pesar de los cambios socioculturales que han afectado espectacularmente la constitución, la distribución y la sanción institucional de los saberes disciplinarios a partir de la segunda mitad del siglo xx (para una discusión sobre esta materia, Moraña, "Estudios literarios y culturales latinoamericanos. Aproximaciones inter/trans/post disciplinarias”).
} 
contribuido a la revisión de algunos supuestos sobre los cuales se sustenta dicha regulación. Entre estos se destaca una noción, casi diríamos material, sólida, del texto. Una noción revestida de prestigio, eje de la tradición y, por consecuencia, del aparato institucional (específicamente escolar) que asegura la preservación y la autoridad de los saberes literarios. Concebir a la literatura como una serie de corpus textuales es un buen ejemplo de esta materialidad indiscutible para muchos. Solo semejante solidez ha sido capaz de suscitar criterios de distribución como los citados arriba: cuerpos textuales cuya materialidad fija y cerrada es capaz de señalar estaciones en el tiempo y espacios en la geografía. Un texto así constituido ha determinado los procedimientos de lectura propios de la crítica literaria ejercida en el dominio de los estudios literarios sancionados por la universidad, al menos en nuestro entorno. Quisiéramos comenzar por exponer los términos de la revisión de este texto materializado en la conciencia de los profesores universitarios especializados en literatura.

La literatura, en tanto campo nocional y disciplina del conocimiento (Escarpit, Hacia una sociología, 257-272) en cuyo territorio se llevan a cabo nuestras responsabilidades como lectores especializados, tiende a estimular la concepción de los diversos constituyentes del discurso literario exclusivamente como texto, es decir, objeto acabado, fijo, significativo y coherente por sí mismo. La "materialidad verbal" del texto le ha conferido a este una posición central entre todos los elementos que concurren en el proceso específico de la comunicación humana, del cual forma parte. La literatura "funciona" sobre la base de textos que se consideran completos por sí mismos en virtud de los códigos lingüísticos y culturales que constituyen sus formas y su estructura. El texto literario se considera significativo gracias a que despliega o pone en movimiento, por así decirlo, el sistema de signos del cual es portador. El alto grado de formalización que caracteriza al texto literario subraya su codificación como un hecho terminado, cerrado, fijo, susceptible de comentarse (Foucault, El orden, 20-24) ${ }^{2}$ como consecuencia de la lec-

\footnotetext{
${ }^{2}$ Hacemos uso del vocablo comentario en el sentido en que lo hizo Foucault cuando explicó uno de los "procedimientos de control y delimitación del discurso" de carácter interno. Este procedimiento supone un texto fundador y otro derivado, posterior, que dice "por fin lo que estaba articulado silenciosamente allá lejos"; un texto derivado
} 
tura, y no como uno más de los elementos que concurren en un proceso firmemente integrado en el ámbito de las interacciones sociales. Un proceso vivo, agónico, irrepetible en virtud de todos los accidentes humanos que concurren en el ejercicio de la escritura. Si tuviéramos que recurrir a una metáfora conceptual con el fin de aludir a la riqueza y a la diversidad de los elementos concurrentes en la escritura, diríamos que las categorías cognitivas dominantes sobre el texto tienden a silenciar el clima de "oralidad" en que este se suscita. A nuestro juicio, la contextualización que ciertas orientaciones influidas por tesis de índole pragmática, hermenéutica y retórica (López Eire, Retórica clásica, 45-63) prescriben en los estudios literarios se cumple mediante la construcción cuidadosa de un escenario histórico y social en el cual, a fin de cuentas, se pone en funcionamiento un sistema de signos disponible de antemano para el autor y codificado por este en el texto. Ni siquiera el principio de indeterminación del texto planteado como consecuencia de una lectura creativa (recepción) parece poner en tela de juicio la pretendida naturaleza sistémica del texto (Hernández, "El texto y el lector", 95-107). La cuota de misterio que se hurta del lector se deposita en algún recoveco de los sistemas que concurren en la materialidad verbal del texto con el fin de aclararlo, de fijar el sentido y conceder al lector crítico la certeza racional de su dictamen, al cual lo obliga la institución de la enseñanza. La escritura del texto literario nubla, y aun borra, el entendimiento de las acciones e interacciones que ocurren gracias al proceso de comunicación del que forma parte y que, necesariamente, relativizan su índole sistémica.

Así concebido, el texto se ha convertido en una categoría primaria a partir de la cual se operan criterios de conceptualización, clasificación, orden y distribución de diversas y complejas actividades propias de la comunicación humana. Tal complejidad y tal diversidad, debido a estas operaciones, han sido reducidas a su dimensión textual y, en consecuencia, han propiciado que esta dimensión se convierta en el fundamento de la configuración conceptual constituida en torno del vocablo

que dice "por primera vez aquello que sin embargo había sido ya dicho" (El orden, 2324). Esta relación paradójica se funda en el supuesto teórico, no siempre explícito, de la estabilidad del sistema de signos constituyente del texto. 
literatura. Así, el lector especializado de la literatura es sobre todo un comentador de los códigos sistematizados y formalizados en los textos que han sido consagrados como parte del dominio de la literatura. La solidez autoritaria del texto es una proyección en nuestro tiempo de la aspiración que los "hombres de letras" abrigaron desde el siglo XVIII, y particularmente durante el siglo XIX en el caso latinoamericano, a propósito de la legislación racional, abstracta y universal del orden de la cultura letrada con base en los modelos sistémicos de la lengua (Ramos, Desencuentros de la modernidad, 35-49) y del derecho. La codificación del derecho y de la gramática se convirtieron en modelos de reducción racional y abstracta de los procesos sociales de índole tradicional que imperaron en el antiguo régimen; procesos sociales discontinuos, irregulares, cordiales, anímicos y agónicos que, como veremos un poco más adelante, se condicen mejor con la experiencia de la comunicación humana tal y como efectivamente la experimentamos cotidianamente. En este sentido, la racionalidad de los dispositivos propios de la escritura y de los sujetos que constituyeron su identidad social y su autoridad civil alrededor de esta combatió frontalmente la atmósfera de oralidad en que realmente ocurre la trama de la vida humana. El aparato educativo que contribuye al sostenimiento y a la reproducción de una configuración conceptual moderna sustentada en modelos sistémicos subraya, por medio de sus numerosos instrumentos (los programas y manuales de estudio, los criterios que organizan las obras de referencia y consulta, los formatos editoriales, las categorías que dictan las efemérides que ritualmente congregan a la comunidad de los eruditos universitarios, etcétera), la pretendida condición fija, cerrada, significativa y coherente por sí misma del texto literario, como si este fuera la realidad última del proceso de comunicación del cual solo es una parte constitutiva.

El prestigio con que la institución literaria (Dubois, L'institution, 19-36, 151-158) inviste al texto también contribuye a hacer todavía más sólida su centralidad y, concomitantemente, a diluir el contorno de la comunicación humana, proceso del cual, en nuestra opinión, no es sino un caso, y en cuyo campo debería implantarse si ha de estudiarse toda su complejidad significativa, en modo alguno circunscrita a los códigos de un texto. Solo en el proceso de la comunicación humana, integrado gracias a los muy diversos elementos constituyentes de sentido que en 
él concurren, textuales y no textuales, encontrarán su lugar adecuado problemas que preocupan desde hace tiempo a los estudios literarios sin haber conseguido del todo convertirse en elementos constituyentes del sentido literario, y no solo meros datos de un escenario histórico y social en el cual se despliegan las potencialidades de los códigos concurrentes en el texto. Los problemas que se plantean a los estudios literarios - sin que estos puedan ofrecer una respuesta satisfactoria desde la perspectiva de un texto sólido, estable, fijo y autónomo - han derivado desde hace varios años hacia la problematización crítica de la inserción compleja del discurso literario en la historia y en la sociedad. ${ }^{3}$ En última instancia, la literatura, si ha de ser significativa para la vida humana tal y como la experimentamos, ha de ser considerada teóricamente como un elemento más de la comunicación que, en opinión del lingüista inglés Roy Harris, es un proceso integrador de actividades de muy diversa índole (Introduction, 28-29).

La literatura es un fenómeno complejo cuya circunscripción teórica a los textos distribuidos y organizados en su dominio es problemática. Los textos literarios en cuya "materialidad verbal" se formalizan códigos lingüísticos y culturales no agotan la experiencia que los seres humanos que los escriben tienen de la literatura, pues esta se encuentra radicalmente integrada en las prácticas constituyentes del orden social y en las diversas tramas de la sociabilidad. Prácticas y tramas no solo correspondientes a lo expresado, sino también a lo no expresado, lo que no ha sido dicho pero que afecta significativamente los términos de la comunicación. Prácticas del orden social y tramas de la sociabilidad que los discursos institucionalizados de los estudios literarios no admiten como parte de su laboratorio crítico, pues no se encuadran en el marco trazado por los presupuestos teóricos que les dan legitimidad.

El sentido que hace inteligible este fenómeno complejo solo puede ser cabalmente comprendido gracias al reconocimiento de su integración radical en el orden social del cual forma parte; más aún: en los procesos especificos mediante los cuales dicho orden social se hace percep-

${ }^{3}$ La necesidad de responder a este problema explica la deriva reciente de una zona considerable de la crítica literaria hacia la llamada historia intelectual (Altamirano, "Ideas para un programa”, 13-24; Dosse, La marcha, 127-179). 
tible para los seres humanos más allá de modelos abstractos. Por ello, sería pertinente que el estudio de la literatura se emplazara en el ámbito del lenguaje (no solo comprendido teóricamente como un sistema de signos), de la escritura (no comprendida como la proyección letrada del sistema de la lengua) y, con toda propiedad, en el de la comunicación humana en cuyo territorio comparecen seres humanos cuya existencia textualizada en modo alguno puede reducirse a los principios teóricos de las lecturas racionales e institucionales de la literatura, sancionadas por la noción de un texto racionalmente constituido. La pretendida autonomía de la literatura, requisito de su habilitación en el campo de las disciplinas del conocimiento, ha operado una separación de los códigos lingüísticos y culturales que se formalizan en el texto literario con respecto de las diversas dimensiones de la vida humana en que tal formalización textual se encuentra verdaderamente radicada.

La compleja formalización y codificación que caracteriza al texto literario tiende a diluir en nosotros la conciencia de interacción humana en que realmente se instaura la literatura, a pesar del aplazamiento en el tiempo y en el espacio con el cual se verifican los procedimientos de lectura y el dictamen crítico. Los métodos de lectura crítica sancionados por los estudios literarios reproducen la debilidad de esta conciencia. Por todo ello, repetimos, resultaría apropiado el emplazamiento del texto literario en el terreno de la comunicación humana, del cual es un caso particular, si no queremos renunciar a una vía de acceso a la comprensión del sentido que un texto comporta para quienes han concurrido en el proceso que lo ha hecho posible.

En consecuencia, la lectura crítica del texto literario, regulada como una práctica social coherente con la "autonomía" del objeto de estudio de la literatura, debería poner en cuestión algunas de sus pautas, especialmente la correspondiente a la separación entre los códigos culturales formalizados en el texto y los fenómenos de contextualización en que tal texto se inserta, gracias a los cuales se integra y cobra sentido para una comunidad humana; ${ }^{4}$ fenómenos de contextualización que se

${ }^{4}$ El concepto de fenómenos de contextualización ha sido tomado en préstamo del taller de trabajo de un lingüista, Roy Harris, ocupado, como es natural en su disciplina, de fenómenos de lengua ocurridos efectivamente en el curso de la conversación entre dos o poco más interlocutores. Esta dimensión del estudio de la lengua, que reviste una 
interesan particularmente en el proceso individual, complejo e irrepetible de realización de la escritura; y, también, el entrenamiento y la acreditación del lector crítico en la interpretación exclusiva de los códigos constituyentes de sentido (sean lingüísticos, semióticos o fundados en archivos culturales transhistóricos).

Nuestra reflexión nos ha llevado a pensar en la (re)integración de los códigos concurrentes en el texto con sus fenómenos de contextualización en los términos de una igualdad radical como constituyentes de sentido de la misma importancia. Esta propuesta tiene como estímulo la perspectiva integral de los signos desarrollada por Roy Harris y la escuela que encabeza en el campo de la lingüística.

The first thing an integrationist will insist on in linguistics is that any viable model of linguistic communication must treat all the activities concerned - not just some of them - as integrated activities. This means that communications must be contextualized. Context is not an optional extra. It is not just a backdrop that can be changed at will, as in theatrical performance (Harris, Introduction, 23).

Así, este artículo adopta y recrea en el dominio de la lectura crítica de textos literarios algunas tesis de la lingüística integral (integrational lingüistics), particularmente las relativas a la fundamental naturaleza integrada del signo, los fenómenos de contextualización y el sentido (Gretsch, "Pragmatics and Integrational Linguistics", 329-331, 336-337). Nuestro propósito supone, en consecuencia, las siguientes operaciones:

1. insertar, con las consecuencias teóricas que ello comporta, el texto literario en el campo general de la comunicación humana, de cuyas interacciones forma parte como un caso particular y como un caso integrado semióticamente a otros;

\footnotetext{
perspectiva radicalmente agónica, nos ha parecido no solo convincente y pertinente desde el campo de los estudios literarios, sino complementaria necesariamente de la noción de contextualización que prima en este campo, centrada en problemas sociales, institucionales y culturales. Esta clase de problemas constituyen sus objetos de trabajo en categorías sistémicas que tienden a reducir la riqueza de los fenómenos en que se integran los signos a los patrones regulares, racionales, concebibles por la inteligencia crítica institucionalizada en el ámbito universitario.
} 
2. criticar la noción de "autonomía literaria" con base en una integración radical de los códigos lingüísticos y culturales que concurren en la formalización del texto con los fenómenos de contextualización en que se inscribe dicha formalización como constituyentes de sentido de diversa índole, pero de la misma importancia en el proceso de comunicación literaria;

3. plantear que la lectura crítica de un texto literario es uno de los términos del proceso de interacción humana propuesto por un acto de escritura ocurrido en el pasado;

3.1 esta interacción, aplazada, diferida, nos obliga a tener en cuenta que el acto de escritura se caracteriza por una zona de indeterminación correspondiente a su propia ejecución, significativa por sí misma en los términos que una sociedad confiera potencial significativo a esta clase de actos; la interpretación de los códigos culturales del texto resultante del acto de escritura es insuficiente para determinar los valores indeterminados, si no es gracias a procedimientos de cuya índole anacrónica con respecto del tiempo del acto de escribir convendría tener plena conciencia. Tales interpretaciones suponen una pérdida, una ausencia, la imposibilidad radical de tener acceso a los fenómenos de contextualización relativos a la dimensión personal del acto de escribir. Expliquemos con cierto detenimiento este problema.

4 de abril de 1984. Este es el enunciado que Winston Smith, personaje de la novela de George Orwell 1984 escribe en el principio de su diario. Con esta cita no queremos traer a cuento la demorada descripción del pasaje en el cual se consignan los preparativos que anteceden al acto de redactar esta frase, sino la interpretación que el lingüista inglés Roy Harris, impulsor de la perspectiva integral de los signos, el lenguaje y la escritura, propuso acerca de tales líneas en su obra Signos de escritura. De acuerdo con Harris, los prolijos preparativos del personaje Winston Smith en los cuales se focaliza la narración de Orwell (la adquisición del cuaderno, la valoración afectiva de sus pastas y de su papel, la ubicación de Smith en el espacio doméstico, las características de la pluma, el sonido de su contacto con el papel, los accidentes afectivos que acompañan su disposición a escribir) sugieren que el acto de escribir 
tiene significación por sí mismo independientemente de las palabras que resulten de su ejecución. Smith lleva a cabo un acto de disidencia; la nimiedad de la frase que textualiza dicho acto (4 de abril de 1984) no hace sino llamar nuestra atención sobre las circunstancias anímicas, morales, políticas y sociales que concurren en el acto de escritura ejecutado por el personaje de Orwell. Roy Harris piensa que:

Una vez que aceptamos la posibilidad de que el acto de escritura pueda ser significante por sí mismo, ya no podemos excluir la posibilidad de que esta significación (esté motivada por circunstancias políticas, sociales, religiosas u otras) pueda, en ciertos contextos, restringir de diverso modo aquello que puede ser escrito. Una teoría de la escritura no debe dejar de lado tales restricciones. Si lo hace, sería culpable de descontextualizar todo el proceso de escritura (Signos, 55$){ }^{5}$

La tesis de Harris aboga en favor de una explicación del acto de escribir desde una perspectiva integral, es decir, un punto de vista que incorpore en el planteamiento del problema de la escritura los fenómenos de contextualización no codificables ni reductibles a sistemas abstractos, habitualmente separados en la lectura crítica del sistema de los signos del lenguaje. El pasaje de la novela de George Orwell que cita Harris es abundante en la consignación de los fenómenos de contextualización que restringen las posibilidades significativas del acto de escribir, necesarios para comprender el sentido disidente y liberador que comporta el modesto enunciado 4 de abril de 1984. Estos fenómenos

\footnotetext{
${ }^{5}$ El uso de las voces restringir y restricción en la traducción española del libro de Harris merece un breve comentario. La discusión de la cual hemos extraído la cita que da pie a esta nota plantea que los presupuestos de la obra de Saussure alimentan una explicación "restringida" de la escritura a la cual se opone la perspectiva integral. Según esta perspectiva, la escritura no solo implica lo que se escribe con base en códigos lingüísticos, sino también el acto mismo de escribir, es decir, las actividades constituyentes de sentido que no contempla el modelo saussureano fundamentado en una formalización sistemática del acto de habla (Harris). Una explicación no restringida es propia de una perspectiva integral que reincorpora en la problematización de la escritura elementos de la contextualización no codificables, diversos, difíciles de reducir a un sistema abstracto. Una teoría no restringida de la escritura incorpora elementos del contexto restrictivos de lo escrito. Tales restricciones son constituyentes de sentido y su índole puede ser biomecánica, macrosocial (instituciones y prácticas sociales) y circunstancial (37).
} 
de contextualización no son un optional extra, un backdrop that can be changed at will, as in theatrical performance, sino las posibilidades mismas de un proceso de comunicación humana que confiere sentido a esos patrones indeterminados, que son los signos, según la postura más extrema de Harris.

Con ser tan valiosa y sugerente para nosotros esta tesis, se pierde de vista en su planteamiento y desarrollo que la rica contextualización de este enunciado se debe a un relato de ficción organizado por un narrador omnisciente que tiene a su alcance lo que habitualmente desconocemos quienes leemos los enunciados de, pongamos por caso, José Enrique Rodó, Pedro Henríquez Ureña, Alfonso Reyes e incluso el mismo Orwell. El lector de los textos producidos por esta clase de escritores carece del caudal de información contextual que, en cambio, nos permite interpretar con seguridad, desde un punto de vista integral, el acto de escritura de Winston Smith. El lector de Reyes, Henríquez Ureña o Rodó (crítico, educado disciplinariamente, entrenado según las pautas de la institución de los estudios literarios) suple la falta de información por medio de, al menos, dos recursos — si es que llega a interesarse en la plataforma enunciativa sobre cuya base se articulan y se difunden los enunciados que lee, como suele ser el caso en el estado actual de la crítica literaria, profundamente afectada por orientaciones pragmáticas de diversa índole.

1. El recurso de la tradición. El lector especializado, educado en una disciplina universitaria próxima al campo nocional de la literatura, se encuentra al tanto de la tradición crítica que se ha conformado alrededor de un escritor como los señalados anteriormente. Entre otras cosas, esta tradición es fuente de discursos que sancionan el lugar social de estos escritores en una comunidad de sentido, y proveen de información contextual a los lectores especializados que se incorporan a dicha comunidad. Si en un principio, tales discursos han sido el producto de una experiencia de lectura crítica, su acumulación ha terminado por convertirlos en una condición de nuevas experiencias de lectura porque suplen de información contextual, es decir, una clase de información que los enunciados literarios no son capaces de proveer y que, no obstante, es necesaria 
para comprender las restricciones que hacen significativas los actos de escritura de los cuales tales enunciados no son sino uno más de los elementos constituyentes de sentido. Información de índole política, social, histórica, religiosa, biográfica, etcétera, tal y como el narrador omnisciente de 1984 provee a Roy Harris acerca del acto de escritura de Winston Smith.

2. La proyección de los valores que constituyen el horizonte de sentido propio del presente del acto de la lectura hacia el pasado del acto de la escritura. El lector suple las deficiencias del texto literario con el propósito de consumar el proceso de comunicación mediante las categorías conceptuales que constituyen en el presente del acto de leer su propia noción de literatura. Por ejemplo, las categorías de autor, escritura, obra y género, históricas en sí mismas, circunstanciales, se revisten de un halo de permanencia más allá de las circunstancias que impone el tiempo y el espacio a la comunicación humana con el fin de normalizar, regularizar y volver coherente para la conciencia del lector un proceso de comunicación textualizado que no es ni regular ni sujeto a normas sistemáticas ni coherente si se toman en cuenta los fenómenos de contextualización que concurrieron en las condiciones de posibilidad significativa del acto de escribir.

En última instancia, el texto literario es la huella insuficiente de un acto de escritura que nos obliga a pensar su peculiar modo de incorporarse en el campo general de la comunicación humana. Los recursos anacrónicos que hemos señalado tienen como propósito reintegrar un texto literario en un acto de escritura cuyas condiciones específicas se han perdido irremediablemente para el presente de la lectura crítica, pero son necesarias para dar sentido a ese texto, para comprenderlo como un proceso pertinente en la comunicación humana. La "invención" del sentido de un texto escrito en el pasado, condición necesaria de su pertinencia en los intereses del presente, no alcanza a resarcir la deficiencia propia de los sistemas lingüísticos y culturales constitutivos de un texto, ni, por tanto, a restituirlo en el escenario complejo de su integración en el campo de la comunicación humana. A pesar de esta imposibilidad consustancial a la lectura crítica, sería conveniente no apartar de la con- 
ciencia de quien lee la naturaleza inventiva de una zona considerable de sus dictámenes críticos. Abundemos a este respecto mediante el esbozo de un problema relativo a la indeterminación de sentido que se vuelve evidente, desde nuestro punto de vista, en tres ensayos del escritor dominicano Pedro Henríquez Ureña.

Los ensayos a los cuales nos referimos corresponden a lo que Rafael Gutiérrez Girardot y Ángel Rama llamaron el "momento de concepción de la cultura militante" de Pedro Henríquez Ureña (Henríquez Ureña, La utopía, 488), plenamente desarrollado en La Plata, ciudad de fuerte y combativa tradición universitaria, próxima a Buenos Aires, donde el escritor dominicano asentó su magisterio y lo desarrolló plenamente en dirección de un enérgico sentido social, doctrinal y político. La ciudad universitaria que era escenario propicio para el cultivo del ideario contenido en el movimiento de reforma de las universidades iniciado en Córdoba en 1918 estimuló a Henríquez Ureña a redactar y publicar páginas en las cuales el americanismo de matriz arielista, regeneracionista y antiimperialista se radicalizó al encontrarse con fuentes de pensamiento social, y aun socialista, que conducirían a nuestro autor a emitir consideraciones críticas acerca de las pautas estructurales del orden social. A este respecto, la experiencia de Pedro Henríquez Ureña como funcionario del primer gobierno estable emanado de la Revolución mexicana estimuló la radicalización de su discurso literario. Precisamente al concluir dicha experiencia, el ensayista dominicano se trasladó a Buenos Aires a mediados de 1924. La todavía incipiente red de intereses y amistades intelectuales que Henríquez Ureña había comenzado a tejer desde 1921 con motivo del Congreso Internacional de Estudiantes celebrado en México, y desde 1922 con ocasión de haber formado parte de la comitiva oficial del ministro revolucionario José Vasconcelos en su viaje de trabajo, representación gubernamental y activismo diplomático en varias naciones sudamericanas, entre ellas Argentina; dicha red, repetimos, le abre la puerta de La Plata, donde se constituirá un cenáculo estudiantil a su alrededor (Henríquez Ureña, $L a$ utopía, 488).

Con pie de imprenta de esta ciudad en 1925, y en las prensas de Estudiantina, se publican en un solo volumen dos conferencias que los criterios y las categorías dominantes de genericidad textual en el siglo $\mathrm{xx}$ 
normalizaron como ensayos: "La utopía de América" y "Patria de la justicia". En el mismo año, en la Revista de Filosofía de Buenos Aires, de acuerdo con la cuidadosa anotación a las obras de nuestro escritor editadas por José Luis Abellán y Ana María Barrenechea, se publicó una obra de la misma índole que las referidas anteriormente: "La Revolución y la cultura en México", también identificada en la historia editorial de Pedro Henríquez Ureña como "La influencia de la Revolución en la vida intelectual de México".

Uno de los soportes más importantes del aparato referencial, argumentativo y persuasivo de estas conferencias-ensayos corresponderá al desarrollo de las políticas públicas de carácter social instrumentadas por el gobierno del general Álvaro Obregón. Una extensión de esta experiencia histórica más radical en el discurso es la que corresponde al breve desempeño de Henríquez Ureña durante los primeros meses de 1924 al frente de la Dirección General de Educación Pública del gobierno del estado de Puebla encabezado por Vicente Lombardo Toledano (Henríquez Ureña, Ensayos, 444). En los hechos, ante el público universitario de la Argentina, Pedro Henríquez Ureña fungió como una especie de delegado honorario de la Revolución mexicana y de la doctrina del Estado como autoridad máxima cuyo mandato constitucional lo califica para garantizar y administrar los derechos de la comunidad política por encima de los derechos de cualquier individuo.

En este complejo escenario es factible comprender el sentido de frases como las siguientes:

Está México ahora en uno de los momentos activos de su vida nacional, momento de crisis y creación. Está haciendo la crítica de su vida pasada; está investigando qué corrientes de su formidable tradición lo arrastran hacia escollos al parecer insuperables y qué fuerzas serían capaces de empujarlo hasta puerto seguro. Y México está creando su vida nueva, afirmando su carácter propio, declarándose apto para fundar su tipo de civilización ("La utopía de América”, Henríquez Ureña, Ensayos, 266).

El texto sigue mediante el desarrollo de la doctrina utópica de Pedro Henríquez Ureña (actividad crítica de la inteligencia dirigida al mejoramiento de lo que se es individualmente y de la forma como se vive so- 
cialmente) (270) proyectada a todo el continente americano. Para llevar a cabo dicha proyección se alega el patrimonio de idealismo magisterial que los libertadores y civilizadores habían depositado en la historia de América. Así, la utopía de América era un programa de acción colectiva consagrado a la "reforma social" y la "justicia económica", y, sobre todo, la plena libertad humana solo asequible por la superación de "los estorbos de la absurda organización económica" y del "lastre de los prejuicios morales y sociales que ahogan la vida espontánea" (271). La ubicación de la referencia al esfuerzo colectivo de México hacia el inicio de "La utopía de América" nos permite alegar plausiblemente que este ejemplo es el modelo del programa utópico prescrito por Henríquez Ureña a todos los americanos.

La condición ejemplar de México se ratifica por nuestro autor en 1925 con motivo de "La Revolución y la cultura en México". En el inicio de este escrito, el ensayista dominicano caracteriza la Revolución como un "movimiento de transformación social". El instrumento más notable de dicha transformación es "la creencia de que toda la población del país debe ir a la escuela, aun cuando este ideal no se realice en pocos años, ni siquiera en una generación" (Ensayos, 254). Luego de reseñar las iniciativas llevadas a cabo por México en este rubro, Henríquez Ureña concluye lo siguiente: "Para el pueblo, en fin, la Revolución ha sido una transformación espiritual. No es solo que se le brinden mejores oportunidades de educación: es que el pueblo ha descubierto que posee derechos, y entre ellos el derecho de educarse" (261). La tesis de este documento se desarrolla en el marco de sentido determinado por las matrices utópica y social de Pedro Henríquez Ureña vigentes durante su "momento de cultura militante". Tales matrices conceptuales no solo se corroboran, sino que se enfatizan en "Patria de la justicia", la conferencia-ensayo que acompaña a "La utopía de América" en la edición de La Plata. El expediente que reúne todas estas pruebas (por así llamar a los elementos biográficos, literarios, sociales, políticos e ideológicos que integran nuestro comentario) llevó a un crítico tan distinguido como Rafael Gutiérrez Girardot a desarrollar el perfil de Pedro Henríquez Ureña desde la perspectiva de un llamamiento a la realización de la utopía efectiva de justicia social en América. Este perfil que estatuye las pautas de lectura social y política de la obra del dominicano 
editada en 1978 por la Biblioteca Ayacucho, presenta un sujeto literario coherente con el clima intelectual de América Latina en los años 70 y de los llamados estudios latinoamericanos.

En esta clase de interpretaciones (coherentes, sistemáticas, racionales) no hay lugar para notas disonantes. La silueta del hombre que escribe se diluye un poco ante el volumen masivo del dictamen racional y coherente de la lectura crítica aun cuando la propia historia literaria arroje indicios suficientes de las vacilaciones y los altibajos de un escritor como Pedro Henríquez Ureña que se ha visto obligado a abandonar el México revolucionario, a romper amistades, a guardar un silencio obligado por los intereses de Estado, a confesarse íntima y discontinuamente con un amigo distinguido, a trasladarse a un país en el que no encuentra un acomodo laboral estable, etcétera. Todos estos factores de la vida del sujeto que escribe no cuentan para la interpretación del prócer americano que desde la literatura aboga por la justicia social, la igualdad económica, el respeto a la autodeterminación cultural de América. La omisión de tales factores en el dictamen crítico de la lectura institucionalizada de Rafael Gutiérrez Girardot (Henríquez Ureña, $L a$ utopía, IX-XXXVII) nos parece problemática porque, a despecho de la coherencia de los testimonios que se organizan para demostrar la doctrina utópica del prócer americano, ha dejado huellas en ciertos lugares textuales. Uno de ellos implica cuestión tan delicada como el referente de la Revolución mexicana en el centro mismo del "momento de la cultura militante" de Pedro Henríquez Ureña.

En "Patria de la justicia" leemos lo siguiente:

México, desde la Revolución de 1910, se ha visto en la dura necesidad de pensar sus problemas: en parte, ha planteado los de distribución de la riqueza y de la cultura; y a medias y a tropezones ha comenzado a buscarles solución; pero no toca siquiera a uno de los mayores: convertir al país de minero en agrícola, para echar las bases de la existencia tranquila, del desarrollo normal, libre de los aleatorios caprichos del metal y del petróleo (Henríquez Ureña, Ensayos, 263).

El texto del cual hemos extraído esta cita se desarrolla en el marco cuyo eje es la doctrina utópica ya referida para el caso de América. El énfasis de este desarrollo es tal que allí se encuentra la frase destacada 
por Ángel Rama en su edición de la obra del dominicano: "El ideal de justicia está antes que el ideal de cultura: es superior el hombre apasionado de justicia al que solo aspira a su propia perfección intelectual" (La utopía, 488-489; Ensayos, 265). Este principio confirma uno de los cambios más espectaculares del orden cultural de la Revolución mexicana, del cual Pedro Henríquez Ureña participa: la primacía del paradigma de los derechos sociales con respecto de las libertades individuales en la gestión del orden social, cuyo máximo responsable es el Estado. A pesar de que los gobiernos de la Revolución mexicana han promovido el nuevo paradigma del orden público, Henríquez Ureña escribió, en el contexto del pesimismo con el cual caracteriza la historia de la América de habla hispana, las profundas reservas que hemos citado a propósito de la Revolución. ¿A qué obedecen estas reservas?

En cualquier caso, los contextos racionales que constituyen la lectura crítica de Pedro Henríquez Ureña encabezada por Gutiérrez Girardot, e institucionalizada materialmente en la edición de Biblioteca Ayacucho, no son suficientes para explicar esta nota disonante textualizada en un lugar tan notable. El texto ha querido comunicarnos algo que se nos escapa, algo inasible desde el punto de vista de los recursos de la racionalidad crítica que los estudios literarios sancionan e institucionalizan por medio de sus métodos de interpretación. Algo que, sin embargo, sabemos que podría encontrarse en el dominio de los accidentes de la persona que aspira a comunicarse gracias al acto de escribir, la persona cuyos altibajos anímicos han sido indicados por sus amigos famosos en el duro trance de acomodarse a un nuevo país, ganarse la vida en condiciones menores a sus grandes facultades intelectuales.

Una lectura del texto literario en el esquema de integración de todos los elementos constituyentes de sentido que concurren en un proceso de comunicación quizá no arroje por el momento certezas por completo diferentes de las que nos obsequia una interpretación atenida a la supuesta autonomía del texto, constituida sobre la suposición teórica de que sus códigos lingüísticos y culturales son suficientes para determinar su significado. Sin embargo, la experiencia de lectura que quisiéramos compartir con quienes tengan en sus manos este artículo supone poner en cuestión las certezas con las cuales intentamos habitualmente en nuestra práctica profesional conferir sentido a la indeterminación y 
los vacíos que un texto nos entrega como reflejo de un acto de comunicación literaria cuyo primer término se encuentra irremediablemente perdido para el presente de la lectura crítica.

El texto literario, con todo y su poderosa codificación lingüística, con todo y su enérgica formalización alimentada en archivos culturales prestigiosos, no es sino uno de los elementos (todo lo valioso que se quiera) constituyentes de sentido de uno de los términos de un acto de comunicación literaria en el cual concurrieron, integralmente, muchos otros elementos constituyentes de sentido, lingüísticos y no lingüísticos, literarios y no literarios, dichos y no dichos, pero que aun en su silencio contribuyeron sustancialmente a volver significativos para un ser humano los códigos formalizados de un texto.

El valor indeterminado para nuestro horizonte de interpretación crítica no nos autoriza ni a eliminar algunos de esos elementos constituyentes de sentido del campo de la literatura, ni a ignorar que sobre su vacío proyectamos configuraciones conceptuales pertenecientes a nuestros propios intereses, a nuestra necesidad de controlar ese vacío y volverlo significativo en los términos de un presente que se ha interesado en un pasado perdido. Nuestra determinación, en tanto críticos literarios, de convertir en presente el pasado de uno de los términos de un acto de comunicación humana de índole literaria, nos recuerda que nuestra propia escritura (el artículo que ahora escribimos y que esperamos que alguien lea) es uno de los términos de la interacción humana, en modo alguno situado en el más allá del conocimiento especializado que algunos estudiosos imaginan para la práctica de su disciplina.

\section{REFERENCIAS}

Altamirano, Carlos, "Ideas para un programa de historia intelectual", en Para un programa de historia intelectual y otros ensayos, Buenos Aires, Siglo XXI, 2005, 13-24.

Dosse, François, La marcha de las ideas. Historia de los intelectuales, historia intelectual [2003], trad. Rafael F. Tomás Llopis, Valencia, Universidad de Valencia, 2006.

Dubois, Jacques, L'institution de la littérature. Introduction à une sociologie, Bruxelles, Éditions Labor, 1978. 
ESCARPIT, Robert et al., Hacia una sociología del hecho literario, trad. Luis Antonio Gil López, Madrid, Edicusa, 1974.

Foucault, Michel, El orden del discurso [1970], Barcelona, Tusquets, 1973.

Gretsch, Cécil, "Pragmatics and Integrational Linguistics", Language and Communication, 29: 4, october 2009, 328-342.

Harris, Roy, "Introduction to Ferdinand de Saussure", Course in General Linguistics [1983], trad. Roy Harris, Chicago, Open Court, 1986, IX-XVI.

HARris, Roy, Introduction to Integrational Linguistics, Oxford, Pergamon, 1998.

HARris, Roy, Signos de escritura [1995], trad. Patricia Willson, Barcelona, Gedisa, 1999.

Harris, Roy y J. Talbot TAYlor, Landmarks in Linguistic Thought I. The Western Tradition from Socrates to Saussure [1989], London-New York, Routledge, $2^{\mathrm{a}}$ ed., 1997.

Henríquez Ureña, Pedro, Ensayos, ed. José Luis Abellán y Ana María Barrenechea, Madrid, ALlCA, 1998 (Colección Archivos, 35).

Henríquez Ureña, Pedro, La utopía de América, comp. Ángel Rama, Rafael Gutiérrez Girardot, Caracas, Biblioteca Ayacucho, 1978.

Hernández, Silvestre Manuel, "El texto y el lector", Fuentes Humanísticas, 41, 2010, 95-107.

LóPEz EIRE, Antonio, Retórica clásica y teoría literaria moderna [1997], Madrid, Arco/Libros, $2^{\mathrm{a}}$ ed, 2002.

MoraÑA, Mabel, "Estudios literarios y culturales latinoamericanos. Aproximaciones inter/trans/post disciplinarias". Texto de la conferencia pronunciada el 7 de noviembre de 2011 en el Centro de Estudios Interdisciplinarios, Universidad Nacional Autónoma de México.

Ramos, Julio, Desencuentros de la modernidad en América Latina. Literatura y política en el siglo XIX, México, Fondo de Cultura Económica, 1989. 